\title{
Time dependent chemistry in Planck clouds?
}

\section{Peter Berczik ${ }^{1,3}$, Peter Bertsyk ${ }^{2,4}$, Orsolya Fehér ${ }^{2}$, Jorma Harju ${ }^{5}$, Toshykazu Onishi ${ }^{6}$ and László Viktor Tóth ${ }^{2}$}

${ }^{1}$ National Astronomical Observatories of China, Chinese Academy of Sciences, Beijing, China.

${ }^{2}$ Department of Astronomy, Lorand Eotvos University, Budapest, Hungary.

${ }^{3}$ National Academy of Sciences of Ukraine, Main Astronomical Observatory, Kyiv, Ukraine.

${ }^{4}$ Department of Physical Chemistry, Lorand Eotvos University, Budapest, Hungary

${ }^{5}$ Department of Physics, University of Helsinki.

${ }^{6}$ Dept. of Physical Science, Osaka Prefecture University, Osaka, Japan.

\begin{abstract}
We present a set of time dependent chemical evolution models (based on the UMIST $\dagger$ astrochemistry 2012 code, McElroy et al. (2013) for a range of initial physical cloud parameters: $10 \mathrm{~K}<\mathrm{T}<20 \mathrm{~K} ; 10^{3} \mathrm{~cm}^{-3}<\mathrm{n}\left(\mathrm{H}_{2}\right)<5 \cdot 10^{4} \mathrm{~cm}^{-3} ; 1<\mathrm{AV}<10$ and with estimated values of scaled interstellar ultraviolet radiation field. We compare our chemical model results with the relative abundances of: $\mathrm{CO}, \mathrm{CH}, \mathrm{OH}, \mathrm{HCO}^{+}, \mathrm{HCN}, \mathrm{HNC}, \mathrm{NH}_{3}, \mathrm{~N}_{2} \mathrm{H}^{+}$and $\mathrm{H}_{2} \mathrm{CO}$ molecules. We find significant time dependent variations of the chemical ratios of: $\mathrm{X}\left(\mathrm{NH}_{3} / \mathrm{H}_{2}\right) ; \mathrm{X}\left(\mathrm{HCO}^{+} / \mathrm{H}_{2}\right)$ and $\mathrm{X}\left(\mathrm{HCO}^{+} / \mathrm{NH}_{3}\right)$. The input physical conditions were taken from Fehér O. et al. (2015) at 16 positions along the TMC- 1 dark cloud. The $\mathrm{NH}_{3}$ and $\mathrm{HCO}^{+}$relative densities based on the observations of Fehér O. et al. (2015) help to find the "chemical age" of the given position in the evolution curves.
\end{abstract}

Keywords. Keyword1, keyword2, keyword3, etc.

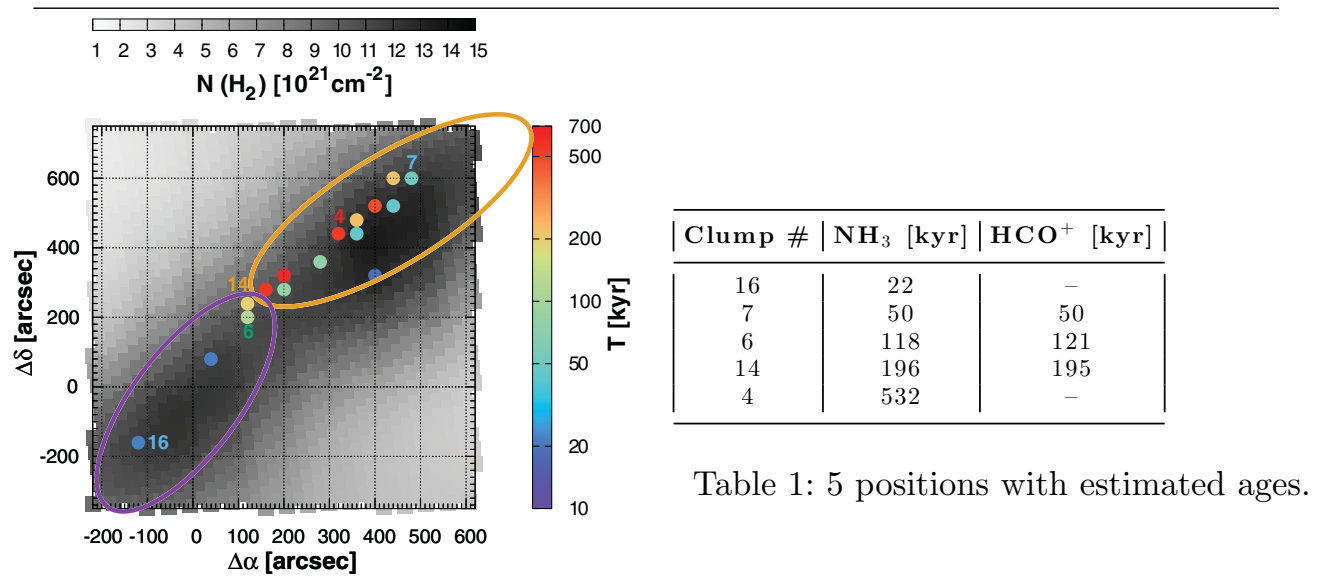

Figure 1: Observed $\mathrm{N}\left(\mathrm{H}_{2}\right)$ column density with positions where "ages" was estimated.

\section{References}

Fehér O., Ward-Thompson, D., Tóth L. V., Kirk, J., Pelkonen, V. M., Zahorecz, S. \& Pintér S. 2015, A\&A , submitted

McElroy, D., Walsh, C., Markwick, A. J., Cordiner, M. A., Smith, K., \& Millar, T. J. 2013, $A \mathscr{E} A, 550, \mathrm{~A} 36$

$\dagger$ UMIST Database for Astrochemistry can be downloaded from the following link: http://www .udfa.net 